\section{Global Journal of Information Technology: Emerging Technologies}

Volume 10, Issue 2, (2020) 113-127
Global Journal of Information Technology: Emerging Technologies

\title{
The moderating effect of analytical decision-making culture on the relationship between business intelligence drivers and organisational agility: Empirical study in Jordanian banking sector
}

Raed Mohd AL-Hanandeh*, Department of Electronic Business, Al Ahliyya Amman University, Amman, Jordan

\section{Suggested Citation:}

AL-Hanandeh, R. M. (2020). The moderating effect of analytical decision-making culture on the relationship between business intelligence drivers and organisational agility: Empirical study in Jordanian banking sector. Global Journal of Information Technology: Emerging Technologies. 10(2), 113-127.

https://doi.org/10.18844/gjit.v10i2.4763

Received June 30, 2020; revised August 13, 2020; accepted October 17, 2020.

Selection and peer review under responsibility of Assoc. Dr. Devkan Kaleci, Inonu University, Turkey.

${ }^{\circ}$ 2020. Birlesik Dunya Yenilik Arastirma ve Yayincilik Merkezi, Lefkosa, Cyprus.

\begin{abstract}
The aim of this paper is to examine the moderating effect of analytical decision-making (ADM) on the relationship between business intelligence drivers [business intelligence (BI), external drivers (EXD) and innovation capacity (INC)] on organisational agility (ORA) in the Jordanian banking sector using mobile banking applications. This study was conducted on four Jordanian banks using mobile banking applications. Approach data were collected in total and 300 out of 360 surveys were valid for the analysis. By carrying out partial least squares hypotheses and applying the confirmatory factor analysis, the item reliability, convergent validity and discriminant validity were assessed. We tested the loadings and the $t$-statistics of the indicators on their corresponding constructs. The findings revealed that there is a certain statistical effect of $\mathrm{BI}$, EXD and INC on ORA; there is an important role of ADM culture as the mediator on the relationship between $\mathrm{BI}, \mathrm{EXD}$ and INC and ORA.
\end{abstract}

Keywords: Business intelligence, external drivers, innovation capacity, organisational agility, mobile banking application.

\footnotetext{
* ADDRESS FOR CORRESPONDENCE: Raed Mohd AL-Hanandeh, Department of Electronic Business, Al Ahliyya Amman University, Amman, Jordan.

E-mail address: $\underline{\text { r.hanandeh@ammanu.edu.jo }}$
} 
AL-Hanandeh, R. M. (2020). The moderating effect of analytical decision-making culture on the relationship between business intelligence drivers and organisational agility: Empirical study in Jordanian banking sector.

Global Journal of Information Technology: Emerging Technologies. 10(2), 113-127. https://doi.org/10.18844/gjit.v10i2.4763

\section{Introduction}

Organisational agility (ORA) considers the fundamental for competency, flexibility and speed, and accesses the real analytical data to meet the needs of the rapidly changing market and increase market shares (Trong et al. 2005). Yusuf et al. [38] revealed that the paradigm of agility is an opportunity to meet unexpected change to influence the organisation profitability, to increase the market shares and to increase the traffic of customers [47]. ORA is structured to predict changes in the business model and they deal with their restructured to design organisations and processes to respond to any new change to achieve the goals of the organisation [2]. Rapid response to market changes leads to economic development and increase in innovation in order to increase the sustainable development in the business model (Arteta and Giachetti, 2004; Lee, Sambamurthy, Lim, and Wei, 2015), [35]. Business intelligence (BI) includes applications, online analytical reports and integrated data to help organisations make better decisions, accumulate user knowledge skills and obtain more experience and in order to help organisation make accurate judgment. $\mathrm{BI}$ summarises those different orientations of measuring $\mathrm{BI}$ maturity leading to a different impact on the orientation of organisation agility [30]. The increases in characteristics of the current context (i.e., resource providers) are considered to be an external change for rapid adaptation and reformation through cooperation to respond to market expansions. As an ability to withstand external changes, it can be seen as being competitive in the global market and has an increasing chance of organisation agility with the increase in potential for profit [22]. Innovation capacity (INC) is an attitude towards uncertainty, and acceptance of new technology to engage in learning and experimenting, to cope with high uncertainty and to respond to opportunities; new initiatives are more likely to be successfully commercialised if they are separated from the core organisation to enable their success [8], However, the transition from the old paradigm to the use of the best IT applications, despite the high cost, leads to the increase in the agility of the company [4]. The entry of globalisation leads to increased economic competition. Companies must maintain competitive advantages in a competitive environment in which companies tend to develop new services or products and develop these specifications in terms of integrating their capacities and resources in order to increase the sensitivity of changes in the market and customers and provide new solutions to deal with dynamic and complex environments [29]. Christensen [8] claimed that ORA refers to the ability of companies to adapt to external variables and to regulate internal processes, in order to reach and interact with customers. ORA is the constant ability to deal with changes that unexpectedly appear in the business environment by increasing speed and innovation that uses changes to improve corporate agility and increase the ability to enter the market proactively, allowing companies to modify their plans and strategies and to organise new business models to gain advantages early in the competition in variable conditions [7]. Changes in the corporate environment require that they modify their procedures and strategies and adapt them very quickly. In a highly competitive environment, corporate competencies are associated with ORA that has profound effects on institutional performance. Companies that are able to respond quickly and innovatively to changes in their business environments have been able to improve their performance, resources and capabilities and increase their products to reach a more flexible market [13], (Ferrier et al., 1999). These initiatives call for agile regulations with strategic and operational decisions to keep pace with environmental changes in markets and products. Decisionmaking is a great deal of flow and analysis of data, information and knowledge as it addresses this information as required in the decision-making process to change the business environment, the continuous processing required to become computerised in terms of the constant flow of information and direct communication with all parties using modern technological applications [12]. Companies and their customers can use the best technological applications and use IT resources to get the same services delivered in real time, enhancing the company's ability to respond to external variables to customers in exploring the needs of customers and to develop new competitive procedures. Technology applications and the use of IT resources allow information sharing between companies and their customers, improving the company's ability to respond quickly to customer needs [16]. Innovative capacity in innovative companies is involved in learning and experimentation, which is able 
AL-Hanandeh, R. M. (2020). The moderating effect of analytical decision-making culture on the relationship between business intelligence drivers and organisational agility: Empirical study in Jordanian banking sector.

Global Journal of Information Technology: Emerging Technologies. 10(2), 113-127. https://doi.org/10.18844/gjit.v10i2.4763

to overcome a high degree of change and is more likely to take on current risks. Thus, innovative companies benefit from the use of advanced technology to exploit opportunities and introduce new models that lead companies to excellence in service delivery to customers [8].

The ability of innovations capacity supported by the best applications and technological programmes leads to the presence of distortions in business models in order to reach new services and products and to create a business environment with innovations to increase the activities provided to achieve this impact on resources without the culture before the executive management and to manage innovation efforts to balance these changes [15]. This research focuses on the technological advances in terms of increasing steadily the number of smartphone users and mobile banking applications that use mobile devices to perform account balances, transfer money and pay bills via mobile devices; smartphones are eliminating the need for increased operational cost and collect data on customer behaviour and preferences; mobile phone applications motivate banks to create unique business models for their users; and the analysis of practical measures as the objective of this study is to address the following research questions: What are the drivers that effect ORA in the banking sector? Thus, this research aims to test the moderator role of analytical decision-making $(A D M)$ in relation to $\mathrm{BI}$, external drivers (EXD), INC and ORA. In order to address this research question, the second section shows a literature review of ORA, BI, EXD and INC, with related hypotheses. Following this, the third section presents the research methodology. In 'Analysis and results' tests the results. The last section finalises the research model and presents the results, implications and future work. Improvement in services and being more agile can be obtaining through customer experience [39].

\section{Theoretical background and hypotheses}

Independent variable drivers in this research consist of $\mathrm{BI}, \mathrm{EXD}$ and INC. $\mathrm{BI}$ is derived from a study by Hribar [17], which provided the examined components, and these components are data integration (BDI) and analytical capabilities (BAC). BI enhances organisational decision-making and processes of turning data into information and then into knowledge [23]. EXD derived from a study by Esposito and Evangelista [10] provided the examined components, and these components are changes in competition (ECC) and changes in customer requirements that push companies for enhancing competitiveness by improving their operational efficiency. INC is to better understand how to create new changes, to adapt mobile digital application, to become agile and to engage in experimenting and coping with high new changes. The dependent variables drivers in this research consists of 'ORA (ORG) represents a new changes that allows firms to adapt and cope with new environment' [24], [35], (Tallon and Pinsonneault, 2011). The moderate the ADM culture can help banks in the analysis of practical measures to improve services without overcoming the richness of complex data to acquire comprehensive business analytics and systematic analytic method for company data [31]. As shown in Figure 1 , we developed a research model to examine organisation agility by using mobile banking applications.

\subsection{Business intelligence (BI)}

Studies have gained from BI systems applied to businesses in recent years; however, the concept has a long history. BI uses elements and processes from other areas, such as the military and government administration, to make extensions to some companies that rely on smart information to learn about customer behaviour [27]. It is important to note that access to information affects not only the decision-making process but also the change in organisational and planning practices to understand, create and share knowledge, and thus can be considered a cultural dimension in corporate policy. Among the most important revenue streams of $\mathrm{Bl}$ are better decisions, improvements in business processes and support for strategic business [41]. 
AL-Hanandeh, R. M. (2020). The moderating effect of analytical decision-making culture on the relationship between business intelligence drivers and organisational agility: Empirical study in Jordanian banking sector.

Global Journal of Information Technology: Emerging Technologies. 10(2), 113-127. https://doi.org/10.18844/gjit.v10i2.4763

$\mathrm{BI}$ is a set of mathematical models and methodological analyses used to extract information and access useful knowledge from raw data to use complex decision-making and analysis. BI applications can improve the insights they provide specifically using data extraction techniques, through simulation and modelling the real world within the framework of the 'system thinking' approach, improving expectations and predictions and contributing to a better understanding of the business dynamics of any organisation [46]. Previous studies have investigated to identify the drivers that determine $\mathrm{BI}$, focusing on the right decision; some articles have empirically tested ORG.

\subsubsection{Data integration (BDI)}

BI systems have emerged as a technological solution to speed up decision support in terms of BDI and analysis, to provide departments with different levels of valuable information and to adapt the decisions and change their business environment [11]. The application of BI systems can improve BDI in many ways, such as easier query and analysis, higher level of interaction, improved data consistency and $\mathrm{BDI}$ processes with other relevant data management activities (online transaction processing). Integrated information include legacy systems, relevance of information and features related to access to information from multiple sources (online transaction processing). The benefits of $\mathrm{BI}$ application are to increase competition, monitor all levels of data from all departments, to make sure that key performance indicators (KPIs) we selected are attainable by marketing BI dashboards that display a wide variety of campaigns marketing performance and web traffic performance. Addressing information content and accessibility separately can provide better relationships between BDI and other drivers of the BI system model [11]. The successful application of the BI system in the banks is used in order to access accurate, timely and integrated data, and to provide data transfer professionals with relevant decision-making information. BDI involves combining technical and business process data residing in different sources collaboration between internal and external entities as one of the main factors contributing to the long-term benefits of enterprise information system. Thus, organisations must analyse several sources when building a Bl system by integrating large amounts of data from multiple sources and different homogeneous BI system [26]. Intelligent business systems provide management levels through data analysis through both operational strategy of the sector and the BDI of normal use with traditional information systems going well; however, for organisational and functional planning, new tools are needed to guide more accurate analysis of business analysis, according to as a set of economic patterns of the banking sector [11]. Thus, we posit the following:

\section{$\mathrm{H}_{1}$ : BDI has a direct positive influence on $O R G$.}

\subsubsection{Analytical capability}

Organisations elevate their BAC to balance between striving organisation capabilities and core business smart competencies to define strategic roadmaps with forecasting insight in the organisation along the analytical capability path. An analytical capability in BI allows users to understand the system. Modern technological development allows institutions to obtain ways to increase the reliance on valuable data within operational systems, which increases the strategic role of $\mathrm{BI}$. BI systems combine analytical tools with data collection and data storage to deliver complex internal and competitive information to planners and decision-makers [28]. In terms of decision support systems, the $\mathrm{BI}$ system is considered as a technology complement that provides BDI and BAC to provide different departments and organisational levels to develop a truly multifaceted strategies to drive continues success, to analysis all type of data using complicated quantitative methods and data, to find opportunities and to improve agility effectiveness [11].

$\mathrm{BI}$ provides BAC (such as querying and online analytical processing) to analyse business-inspired business data and design $\mathrm{BI}$ system models and BI review. For the quality of the BI system, we have designed the $\mathrm{BI}$ system maturity model consisting of two factors of the first class: BDI and BAC. With the building of $\mathrm{BDI}$, we can measure the level of data to make analytical decisions within organisations 
AL-Hanandeh, R. M. (2020). The moderating effect of analytical decision-making culture on the relationship between business intelligence drivers and organisational agility: Empirical study in Jordanian banking sector.

Global Journal of Information Technology: Emerging Technologies. 10(2), 113-127. https://doi.org/10.18844/gjit.v10i2.4763

through a set of common factors, such as leadership and data investments [48]; thus, we posit the following:

$\mathrm{H}_{2}$ : BDI has a direct positive influence on ORG.

\subsection{External changes}

Organisation strategy is adapted based on some drivers that lead the organisation to responds to the broader waves of changes and towards more opportunities. These drivers force the organisation to update their strategies [47]. Teece et al. [42] define external competences to address rapidly changing environments. The factor of external changes consists of five constructs determined by Tseng and Lin [43] for market volatility, intense competition and changes in customer requirements caused by demands for customisation.

\subsubsection{Changes in competition (ECC)}

The process constitutes the core business to be competitive; organisations are aiming to modify their business model to be more adaptable and to be integrated with ORG; ECC is a permanent in work environments due to technological progress, increasing regulations, challenges of globalisation, slowing global economy and increasing competition. Developing competencies within organisations creates a competitive environment for changing the competitive environment [21]. The competitive change of creating new opportunities for customers has increased by changing strategies and increasing market shares.

An organisation adopts a policy of change in order to create a competitive environment within the markets in order to meet the needs of consumers. Creating exceptional value for customers is a strategic corporate necessity. With strong competition in many markets, meeting the needs of consumers has become a key factor for success [25]. The pressure to increase competition with foreign products, the introduction of new products by competitors, the contracting of customers and the rapid increase in the information and communication applications industry on companies prompt many banks and companies to improve their efficiency in order to increase competition opportunities (Vázquez-Bustelo et al., 2007). Thus, we posit the following:

$\mathrm{H}_{3}$ : ECC has a direct positive influence on ORG.

\subsubsection{Changes in marketplace (ECM)}

ECM and the strength of the market indicate the company's ability to conduct good operational activities with partners and open channels and markets to adapt or respond to changes within the market in an agile way, i.e., the ability to deliver products and target individuals according to their needs and create innovative services in a timely and cost-effective manner [22]. Instead, market interest should be seen as an indirect determinant of customer behaviour, while recognising that the change of other overlapping operations affects the increased correlation between interest and market behaviour [3]. Market research is a powerful influence of the governance and behaviour of the nature of work, which leads to environmental concern and increases consumption for the development of products, where many customers focus on the relationship between perceived consumer behaviour and individual efforts that can make a difference in solving the needs of markets. Organisations have recognised the potential of the new business model where they keep updating their strategies by adding the marketplace to their business operations, the context of creating new marketplaces through the impact of the individuals on the market (Cho et al., 2013). Thus, we posit the following:

$\mathrm{H}_{4}$ : ECM has a direct positive influence on ORG. 
AL-Hanandeh, R. M. (2020). The moderating effect of analytical decision-making culture on the relationship between business intelligence drivers and organisational agility: Empirical study in Jordanian banking sector.

Global Journal of Information Technology: Emerging Technologies. 10(2), 113-127. https://doi.org/10.18844/gjit.v10i2.4763

\subsection{Innovation capacity (INC)}

INC holds strong implications and capabilities of the organisations. INC depends on the effective utilisation of resources. INC is the ability of companies to innovate critically and the use of technological applications and the integration of all activities of companies to become more flexible and simple. Information technology and institutional innovation are two factors that renew the company and adapt to external variables. The rapid enhancement of companies' ability to innovate will directly impact ORG and mitigate the impact of IT applications' capabilities (Liu et al., 2011). INC differs among most companies in terms of using the best technological applications of less creative companies. ORG is likely to share learning and skills and be able to overcome changes. Innovative companies use digital platforms to respond to the opportunities and threats they face, as well as how to embrace innovations. Some studies have called for the integration of the best modern creations and the use of other IT organisations such as the creation of new channels of communication to reach markets or customers where they require the company to increase the company's existing resources and change business models in new and innovative ways and increase research and development efforts. Information technology arises from business units and requires the use of new technological applications to rethink organisational systems and activities. New business models can succeed in INC efforts to achieve this resource impact and use best business practices [15]. Thus, we posit the following:

$\mathrm{H}_{5}$ : INC has a direct positive influence on ORG.

\subsection{The moderating effect of ADM culture}

The ADM culture was analysed to give details of $\mathrm{BI}$ systems compared to operational information systems. It focuses on the processing of activities and effective information analysis is a system of $\mathrm{BI}$ that is one of the best systems for data analysis, which mainly supports the decision-making process and activities that need to be known better. Knowledge-intensive activities need less structured processes; the $\mathrm{BI}$ environment faces most of the challenges in ensuring the quality of information content when looking at the success of the BI system [48].

Studies have focused on the behaviour of the activation of companies to use information systems. These institutions rely on the implementation of decision support systems to reach the best parameters provided to the decision, to adopt the appropriate decision, to support the women and to increase the expectations and adoption in order to make the organisation excel and change and to build new products in order to increase the capacity of the company. To reach the largest number of customers after analysing the appropriate decisions in order to improve the provision of information to decision-makers and support their decision-making activities that measure the culture of ADM gives companies the appropriate decisions to adopt [37].

Thus, we posit the following:

$\mathrm{H}_{6}$ : ADM moderates the effect of business intelligence drivers (BID) on ORA such that the effect of $B I D$ on ORG is stronger when ADM increases.

We have mentioned five determinants from BID, EXD and INC. Thus, we posit the following:

$\mathrm{H}_{6 \mathrm{a}}$ : ADM moderates the effect of EDI on ORG such that the effect of EDI on ORG is stronger when ADM increases.

$\mathrm{H}_{6 \mathrm{~b}}$ : ADM moderates the effect of BAC on ORG such that the effect of BAC on ORG is stronger when ADM increases.

$\mathrm{H}_{6 c}: A D M$ moderates the effect of ECC on ORG such that the effect of ECC on ORG is stronger when ADM increases. 
AL-Hanandeh, R. M. (2020). The moderating effect of analytical decision-making culture on the relationship between business intelligence drivers and organisational agility: Empirical study in Jordanian banking sector.

Global Journal of Information Technology: Emerging Technologies. 10(2), 113-127. https://doi.org/10.18844/gjit.v10i2.4763

$\mathrm{H}_{6 \mathrm{~d}}$ : ADM moderates the effect of ECM on ORG such that the effect of ECM on ORG is stronger when ADM increases.

$\mathrm{H}_{6 \mathrm{e}}:$ ADM moderates the effect of INC on ORG such that the effect of INC on ORG is stronger when ADM increases.

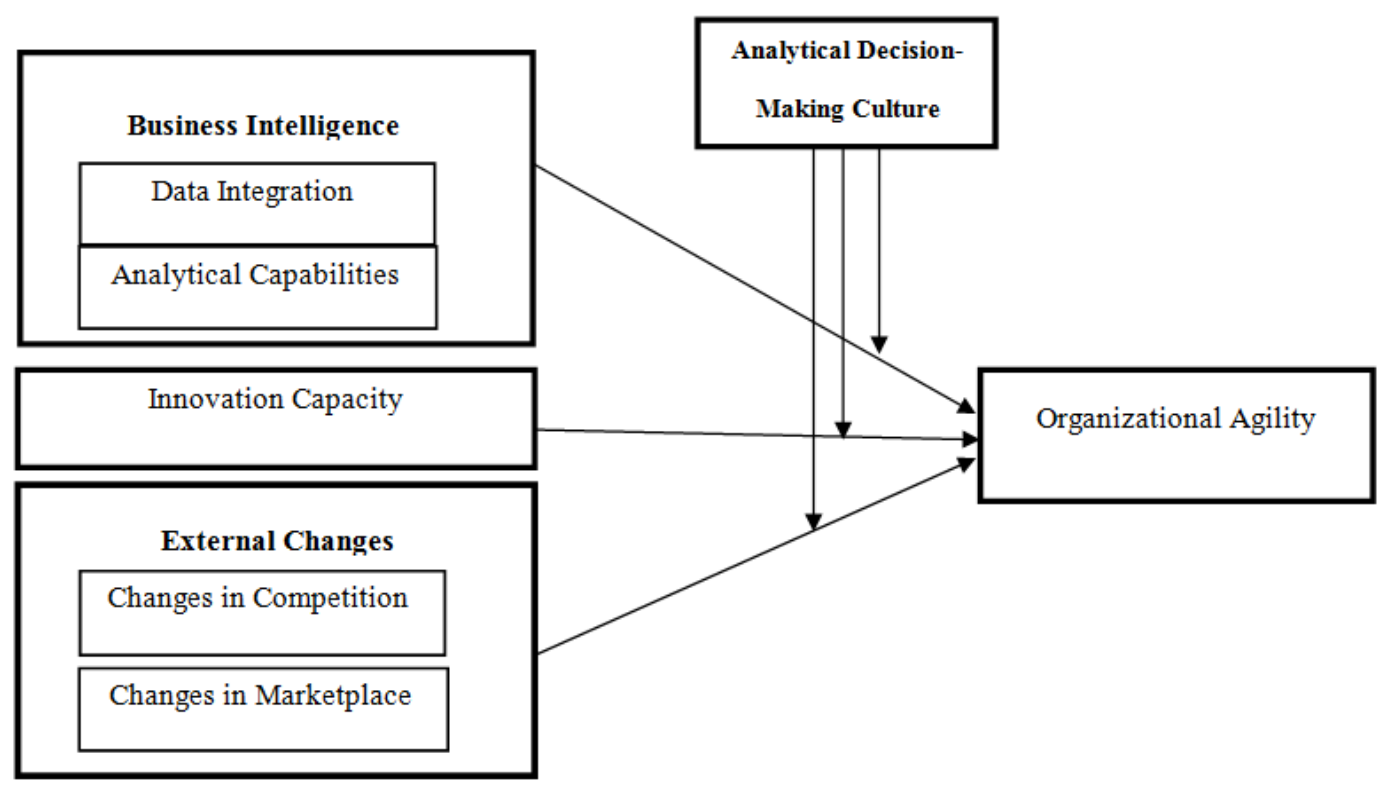

Figure.1 Research model

\section{Methods}

SEM was used to validate the current study model and test the research hypotheses. We collected the required data by using a descriptive cross-sectional survey as shown in Figure 1. Based on the services offered by banks in Jordan, we selected the employees from banks as our sample. The questionnaire survey was allocated to 220 employees from Jordanian banks.

\subsection{Measurement}

This study established certain measures related to organisation agility, and we adapted prior survey questions to guarantee consistency in context to ensure the validity and reliability of the constructs [40]. The questionnaire was distributed to employees of different banks offering mobile banking applications. The questionnaire was measured on a 7-point Likert scale, which measured the main constructs of the conceptual model.

The measurement of $\mathrm{BI}$ was proposed by Hribar [17] and it includes two measurement items: the measure of EDI, proposed by Seddon et al. [32], which includes two items regarding mobile application technology and the measure for EAC, proposed by Trkman et al. [33], which includes six items proposed to reflect an organisation's BAC to rapidly change its internal model to find out demands or market changes. The measure for EXC proposed by Tseng and Lin [43] consists of two drivers: ECC, which includes three items related to new initiatives of competitors and increasing pressure on cost, and ECM, which includes three items related to decreasing new products time to market, increasing rate of change in product models and product lifetime shrinkage. The measure for INC includes four items proposed by Hurley and Hult [19]: the firms encourages and seeks out innovative ideas from its employees, such as creativity and risk taking, to get value from technological innovations in its banking sector. The ORG scales were proposed by Roberts and Grover [35], which 
AL-Hanandeh, R. M. (2020). The moderating effect of analytical decision-making culture on the relationship between business intelligence drivers and organisational agility: Empirical study in Jordanian banking sector.

Global Journal of Information Technology: Emerging Technologies. 10(2), 113-127. https://doi.org/10.18844/gjit.v10i2.4763

includes four items that cope with and respond to changes in our customers' service needs, quickly scale to support fluctuations in market demand and quickly make necessary alternative arrangements and internal adjustments. For moderating variables, the ADM culture proposed by de Alwis and Higgins [37] measures the questionnaire items shown in Appendix A.

\subsection{Data collection}

The questionnaire was distributed to the staff of the Jordanian banking sector. The current study consist of two parts: the theoretical, which relied on the scientific studies concerned with the variables, and the practical, which relied on the descriptive and analytical methods to collect data and test hypotheses. The framework and questionnaire were used to collect data to test the proposed research model. The questionnaires were delivered to 15 branches that participated in the survey. 200 respondents participated and answered the questionnaire to test the hypotheses. Most of the respondents were university educated (100\%); however, they are not allowed to be in this position without a university degree, to be more familiar with banking mobile applications. The majority of the respondents were aged $21-45$ years old, and consisted of male (60\%) and female (40\%)participants, as explained in Table 1.

Table 1. Demographic information

\begin{tabular}{lc}
\hline \multicolumn{1}{c}{ Item/category } & Frequency (ratio) \\
\hline Gender & \\
Male & $120(60 \%)$ \\
Female & $80(40 \%)$ \\
Age & \\
$21-25$ & 55 \\
$26-30$ & 50 \\
$30-35$ older & 95 \\
Education level & \\
Bachelor's degree & 155 \\
Master's degree & 40 \\
Doctoral degree & 5 \\
\hline
\end{tabular}

\section{Analysis and results}

\subsection{Measurement model}

confirmatory factor analysis (CFA) is a statistical technique used to verify the factor structure of a set of observed variables. CFA was used to assess item reliability and convergent validity. In order to test convergent validity, the factors of corresponding constructs should be above 0.70 [6]. The average variance extracted (AVE) score should be above 0.50 [14] and Cronbach's $\alpha$ should be above 0.70 [5]. CFA allows the researcher to test the hypothesis that the relationship between observed variables and their underlying latent constructs exists; we tested $t$-statistics for the estimated value of a parameter from the hypothesised value [34], (Wang et al., 2015). The composite reliability used to test the construct reliability should be equal or above 0.7 and indicating adequately all items were above 0.7. Table 2 shows that all the values of Cronbach's $\alpha$ are larger than 0.70 and AVE is larger than 0.50 for all constructs; so all constructs are satisfactory. Items were removed because of their low loading values below 0.4 [18]; the items removed are BDI1 and BAC1 as shown in Table 2.

Discriminate validity determined that the square root of the AVE was above 0.7, and exceeded all other cross-correlations for each construct were larger than the numbers that were not on the diagonal as shown in Table 4. We checked whether each latent variable shares more variance with its own measurement variables or with other constructs in order to measure discriminant validity [45] as shown in Table 3. The requirement of the discriminant validity construct should be above the 
AL-Hanandeh, R. M. (2020). The moderating effect of analytical decision-making culture on the relationship between business intelligence drivers and organisational agility: Empirical study in Jordanian banking sector.

Global Journal of Information Technology: Emerging Technologies. 10(2), 113-127. https://doi.org/10.18844/gjit.v10i2.4763

measurement error variance. To test the common method bias in the study, the following technique and error tests were used like a questionnaire and investigation to check the correlation matrix among the latent variables [9]. The results showed that the highest covariance explained was $21 \%$, which is less than $50 \%$ of the variance, indicating that there is no problem of common method bias in our study as shown in Table 4.

Table 2. Cross-loading

\begin{tabular}{lccccccc}
\hline & BDI & BAC & ECC & ECM & INC & ADM & ORA \\
\hline BDI2 & $\mathbf{0 . 9 0}$ & 0.30 & 0.02 & 0.34 & 0.22 & -0.22 & -0.21 \\
BDI3 & $\mathbf{0 . 8 4}$ & 0.20 & 0.03 & 0.27 & 0.30 & -0.42 & 0.19 \\
BAC2 & 0.09 & $\mathbf{0 . 8 2}$ & 0.04 & 0.09 & 0.50 & 0.22 & 0.25 \\
BAC3 & 0.05 & $\mathbf{0 . 7 9}$ & 0.05 & 0.15 & 0.35 & 0.32 & 0.53 \\
BAC4 & 0.04 & $\mathbf{0 . 9 2}$ & 0.21 & 0.16 & 0.45 & 0.35 & 0.07 \\
BAC5 & 0.27 & $\mathbf{0 . 7 5}$ & 0.04 & 0.11 & 0.43 & 0.54 & 0.02 \\
BAC6 & 0.32 & $\mathbf{0 . 8 0}$ & 0.07 & 0.08 & 0.31 & 0.35 & 0.25 \\
ECC1 & 0.19 & 0.27 & $\mathbf{0 . 7 8}$ & 0.07 & 0.36 & 0.37 & -0.04 \\
ECC2 & 0.23 & 007 & $\mathbf{0 . 6 9}$ & 0.02 & 0.21 & 0.40 & 0.45 \\
ECC3 & 0.14 & 0.17 & $\mathbf{0 . 8 4}$ & 0.25 & 0.32 & 0.21 & 0.30 \\
ECM1 & 0.53 & 0.16 & 0.23 & $\mathbf{0 . 9 1}$ & 0.45 & 0.23 & 0.32 \\
ECM2 & 0.44 & 0.02 & 0.35 & $\mathbf{0 . 9 0}$ & 0.34 & 0.34 & 0.45 \\
ECM3 & 0.30 & 0.25 & 0.23 & $\mathbf{0 . 8 7}$ & 0.51 & 0.09 & 0.52 \\
INC1 & 0.02 & 0.32 & 0.13 & -0.02 & $\mathbf{0 . 8 0}$ & 0.02 & 0.09 \\
INC2 & 0.08 & 0.36 & 0.32 & -0.14 & $\mathbf{0 . 7 1}$ & 0.20 & 0.08 \\
INC3 & 0.20 & 0.01 & 0.15 & -0.13 & $\mathbf{0 . 8 3}$ & 0.20 & 0.02 \\
INC4 & 0.15 & 0.02 & 0.22 & 0.34 & $\mathbf{0 . 9 0}$ & 0.30 & 0.20 \\
ADM1 & 0.32 & 0.03 & 0.25 & 0.45 & 0.45 & $\mathbf{0 . 7 0}$ & 0.26 \\
ADM2 & 0.04 & 0.02 & 0.32 & 0.23 & 0.42 & $\mathbf{0 . 7 6}$ & 0.33 \\
ADM3 & 0.06 & 0.06 & 0.11 & 0.32 & 0.30 & $\mathbf{0 . 8 0}$ & 0.41 \\
ORA1 & -0.33 & 0.03 & 0.09 & 0.38 & -0.02 & 0.05 & $\mathbf{0 . 6 8}$ \\
ORA2 & -0.25 & 0.13 & 0.02 & 0.16 & -0.04 & 0.07 & $\mathbf{0 . 9 0}$ \\
ORA3 & 0.15 & 0.17 & 0.01 & 0.09 & 0.40 & 0.08 & $\mathbf{0 . 8 6}$ \\
ORA4 & 0.09 & 0.32 & 0.03 & 0.02 & 0.45 & 0.13 & $\mathbf{0 . 9 0}$ \\
\hline SOme & & 0.35
\end{tabular}

Some of the items were deleted due to poor loading $(<0.70)$.

$\mathrm{BDI}=$ Data integration; $\mathrm{BAC}=$ Analytical capabilities; $\mathrm{ECC}=$ Changes in competition; $\mathrm{ECM}=$ Changes in marketplace; INC = Innovation capacity; $A D M=$ Analytical decision-making culture; ORA = Organisational agility. Note: Bold numbers indicate item loadings on the assigned constructs.

Table 3. Item convergent validity and reliability

\begin{tabular}{lcc}
\hline Construct & AVE & Cronbach's alpha \\
\hline BDI & 0.811 & 0.922 \\
BAC & 0.702 & 0.901 \\
ECM & 0.721 & 0.987 \\
ECC & 0.590 & 0.823 \\
INC & 0.665 & 0.755 \\
ADM & 0.725 & 0.795 \\
ORA & 0.775 & 0.845 \\
\hline
\end{tabular}

Table 4. Discriminant validity

\begin{tabular}{lcccccccc}
\hline & AVE & BDI & BAC & ECC & ECM & INC & ADM & ORA \\
\hline BDI & 0.811 & $\mathbf{0 . 8 7}$ & & & & & & \\
BAC & 0.702 & 0.05 & $\mathbf{0 . 8 2}$ & & & & & \\
ECC & 0.721 & 0.19 & 0.17 & $\mathbf{0 . 7 7}$ & & & &
\end{tabular}


AL-Hanandeh, R. M. (2020). The moderating effect of analytical decision-making culture on the relationship between business intelligence drivers and organisational agility: Empirical study in Jordanian banking sector.

Global Journal of Information Technology: Emerging Technologies. 10(2), 113-127. https://doi.org/10.18844/gjit.v10i2.4763

\begin{tabular}{lcccccccc} 
ECM & 0.590 & 0.42 & 0.14 & 0.41 & $\mathbf{0 . 8 9}$ & & & \\
INC & 0.665 & 0.11 & 0.18 & 0.21 & 013 & $\mathbf{0 . 8 1}$ & & \\
ADM & 0.725 & 0.14 & 0.04 & 0.33 & 0.33 & 0.40 & $\mathbf{0 . 7 5}$ & \\
ORA & 0.775 & -0.17 & 0.16 & 0.04 & 0.16 & -0.45 & 0.083 & $\mathbf{0 . 8 4}$ \\
\hline
\end{tabular}

\subsection{Test of the structural model}

Our structural model used the partial least squares -SEM to test the theoretical model structure developed from BID on organisation agility to study the influence of mobile application in the banking sector. The results show that BDI, BAC, ECC, ECM and INC positively influenced ORG, thus supporting $\mathrm{H} 1, \mathrm{H} 2, \mathrm{H} 3, \mathrm{H} 4$ and $\mathrm{H} 5$, as indicated in Table 5, to analyse the moderating effect of ADM, which has strong significant moderating effects between drivers from BID on ORG. The results related to all previous studies have an effect of moderating, as indicated in Table 6.

Table 5. Hypotheses and tests

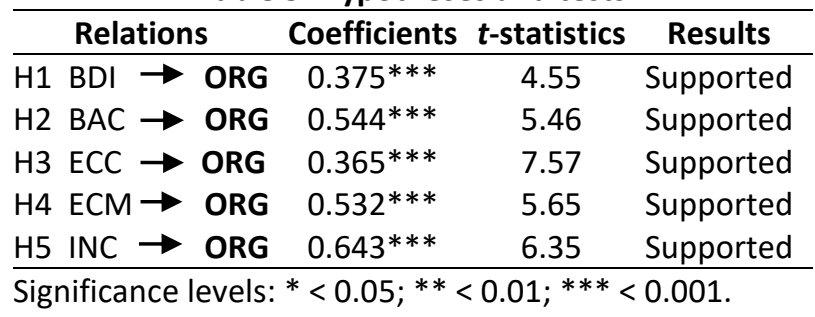

Table 6. Analysis result of the moderating role

\begin{tabular}{cccc}
\hline Relations & Coefficients & t-statistics & Results \\
\hline H6a BDI* ADM $\rightarrow$ ORG & $0.432^{*}$ & 4.33 & supported \\
H6b BAC*ADM $\rightarrow$ ORG & $0.344^{* * *}$ & 3.52 & Supported \\
H6c ECC *ADM $\rightarrow$ ORG & $0.527^{* *}$ & 5.63 & Supported \\
H6d ECM *ADM $\rightarrow$ ORG & $0.472^{*}$ & 4.28 & Supported \\
H6e INC * ADM $\rightarrow$ ORG & $0.478^{* *}$ & 3.45 & Supported \\
\hline
\end{tabular}

Significance levels: ${ }^{*}<0.05 ; * *<0.01 ; * * * 0.001$.

\section{Discussion}

The main objective of this study was to test the EBD effect on ORG by using mobile banking applications. This study supported our expectation to show that the drivers of BI like EDI (H1), and BAC (H3) have a strong support on ORG. Most of the respondents have a bachelor's degree, making it easy to deal with mobile banking applications as one of the reductions of operational costs. The development of smart mobile banking applications make their customers feel comfortable by making transactions for shopping and transferring to different accounts, instant messaging and viewing transaction history [11]. 'The big decision-makers are really leaning on the idea of Mobile technology is taking over and there is a digital-first movement that is taking hold in the marketplace,' and 'have a burning need to innovate faster but have been very successful with digital innovation through inhouse efforts'.

Mobile banking application allows banks to 'develop a much more agile and a much more customer demand and more modernised experience for the customer.' We assume that mobile banking applications will become easier to use and interact and provide more functionality for customers and accelerate banking to customers to obtain more feedback from customer experiences in order to become more enriched and data-informed. This study indicated that the strong effect of BID and design of mobile banking application perceived ease of interaction and more applicable, the strong 
AL-Hanandeh, R. M. (2020). The moderating effect of analytical decision-making culture on the relationship between business intelligence drivers and organisational agility: Empirical study in Jordanian banking sector.

Global Journal of Information Technology: Emerging Technologies. 10(2), 113-127. https://doi.org/10.18844/gjit.v10i2.4763

effect of EXD and ORG to contribute in new solution. Banks started implementing new technology to simplify processes through mobile applications to help banks to expose business model data that have been traditionally flow up in complex analytical core systems and to find actually quite different behaviours in their buying demands and motivators; so banks will increasingly invest in $\mathrm{BI}$ to become more agile and to maintain lean operations while offering new exceptional customer experience at lower costs and targeting demographic-based clusters, such as aspirations, income and transaction and targeting customers based on lifestyles, and to develop a personal structure communication model. To upgrade the level of innovative capacity structure until it reaches advanced analytics and digital technologies, we found that there is moderating effect of ADM on the relationship between BID and ORG.

\subsection{Theoretical and practical implications limitation and future research}

This study reflects the effect of BID on ORG by using mobile banking application in the banking sector, and maintains reflections on the practical field, in particular, because it has helped to expand our understanding of the factors of three dimensions (BI, EXD and INC). The contribution of new drivers of $\mathrm{BI}$ is obtained from previous studies. The obtained data regarding $\mathrm{BI}$ drivers from several studies are affected by different variables applied in other studies. The structured research model consisting of the different factors, firstly BI, EXD and INC, and data collected from distributed surveys in the banking sector. To increase the quality of information from data collection we can use other platforms, such as Chatbot technology and customer relationship management. The feedback was obtained from employees working in different banks' departments, and this mobile banking application adapted new agility towards an increase in the new service. This study contributed to different banks and the applied variables give the organisation the agility to change any business model. The use of the mobile banking application gives the banking sector some kind of analytical data to adapt the best business model. In order to upgrade organisation agility, the information technology department and marketing department should recruit qualified people to teach and encourage the customers how to use the applications and to increase the awareness of using the application that will reflect the use of a new model and tactics towards sustainability.

The limitations in this study are the awareness of using mobile application should be raised among customers. Second, our study reflects the feedback of some banks and not all banks in Jordan use mobile banking application technology; so the data are restricted to a small sample; the results give positive support of moderated variables due to the importance of using this technology. Future research could benefit by increasing the number of customer using this kind of technology and some other online applications, like Chatbot, to increase the agility towards the competitiveness. Since this study is carried out in Jordan, this research also includes several limitations, not all banks implement mobile application technology; in addition to that, not all customers are able to use mobile applications due to several reasons, such as it is not easy to use, security and privacy reasons, preventing them from using this kind of applications. Furthermore, it is also important to compare the results in different countries using same technology; Future research should be carry out by using the longitudinal method to analyse and observe the change in consumers' behaviour over time.

\section{Conclusion}

Mobile banking applications are important to innovate and develop new solutions that benefit from data, analytics, digital technologies and new platforms that are more important than previous releases. The new innovation is expanding the range of services provided by offering proactive new solutions. Mobile banking applications are strategically advanced and responsive to consumer behaviour, expectations and needs in order to increase the market for greater competitiveness in the banking sector. The adoption of mobile applications has led to increasing innovation and collaboration, which could include more than just financial services to improve consumer behaviour. The adoption of mobile applications has made customer behaviour and needs an essential part of the 
AL-Hanandeh, R. M. (2020). The moderating effect of analytical decision-making culture on the relationship between business intelligence drivers and organisational agility: Empirical study in Jordanian banking sector.

Global Journal of Information Technology: Emerging Technologies. 10(2), 113-127. https://doi.org/10.18844/gjit.v10i2.4763

banking strategy placing an increasing emphasis on customer value propositions. In other words, if the enhanced value is not part of the open banking consumer view, the customer will not allow the data to be shared. Instead, companies that offer the best value propositions to consumers will be winning in the relationship.

\section{References}

[1] A. Popovič, P. S. Coelho, and J. Jaklic, "The impact of business intelligence system maturity on information quality," Inf. Res., vol. 14, no. 4, 2009.

[2] M. Balaji, V. Velmurugan, G. Sivabalan, V. S. Ilayaraja, M. Prapa, and V. Mythily, "ASCTM approach for enterprise agility," Procedia Eng., vol. 97, pp. 2222-2231, 2014.

[3] S. Bamberg, "How does environmental concern influence specific environmentally related behaviors? A new answer to an old question," J. Environ. Psychol., vol. 23, no. 1, pp. 21-32, 2003.

[4] D. A. Battleson, B. C. West, J. Kim, B. Ramesh, and P. S. Robinson, "Achieving dynamic capabilities with cloud computing: An empirical investigation," Eur. J. Inf. Syst., vol. 25, no. 3, pp. 209-230, Nov. 2016.

[5] A. Bhattacherjee and S. C. Park, "Why end-users move to the cloud: A migration-theoretic analysis," Eur. J. Inf. Syst., vol. 23, no. 3, pp. 357-372, 2014.

[6] W. W. Chin, B. Marcolin, and P. R. Newsted, "A partial least squares latent variable modeling approach for measuring interaction effects: Results from a Monte Carlo simulation study and an electronic-mail emotion/adoption study, "Inf. Syst. Res., vol. 14, no. 2, pp. 189-217, 2003.

[7] A. Chakravarty, R. Grewal, and V. Sambamurthy, "Information technology competencies, organizational agility, and firm performance: Enabling and facilitating roles," Inf. Syst. Res., vol. 24, no. 4, pp. 976-997, Oct. 2013.

[8] C. M. Christensen, The Innovator's Dilemma: When New Technologies Cause Great Firms to Fail. New York, NY, USA: Harvard Business Review Press, 2013.

[9] A. Chen, Y. Lu, and B. Wang, "Customers' purchase decision-making process in social commerce: A social learning perspective," Int. J. Inf. Manage., vol. 37, no. 6, pp. 627-638, 2017.

[10] E. Esposito and P. Evangelista, "Investigating virtual enterprise models: Literature review and empirical findings," Int. J. Prod. Econ., vol. 148 , pp. 145-157, Feb. 2014.

[11] E. Turban, R. Sharda, and D. Delen, Decision Support and Business Intelligence Systems, 9th ed. Upper Saddle River, NJ, USA: Prentice-Hall, 2010.

[12] Y. Farjami and R. Molanapour, Business Intelligence (From Idea to Practice), 1st ed. New York, NY, USA: AtiNegar Press, 2015.

[13] W. J. Ferrier and D. W. Lyon, "Competitive repertoire simplicity and firm performance: The moderating role of top management team heterogeneity," Manage. Decis. Econ., vol. 25, nos. 6-7, pp. 317-327, 2004.

[14] C. Fornell and D. F. Larcker, "Structural equation models with unobservable variables and measurement error: Algebra and statistics," J. Marketing Res., vol. 18, no. 3, pp. 382-389, 1981.

[15] V. Govindarajan and C. Trimble, Ten Rules for Strategic Innovators: From Idea to Execution. Boston, MA, USA: Harvard Business School Press, 2005.

[16] K. C. Gonul, D. R. Nowicki, B. Sauser, and W. S. Randall "Impact of cloud based information sharing on hospital supply chain performance: A system dynamics framework," Int. J. Prod. Econ., pp. 195168-195185, 2018.

[17] I. Hribar Rajteri, "Overview of business intelligence maturity models," Management, vol. 15, no. 1, pp. 4767, 2010.

[18] J. Hulland, "Use of partial least squares (PLS) in strategic management research: A review of four recent studies," Strategic Manage. J., vol. 20, no. 2, pp. 195-204, 1999. 
AL-Hanandeh, R. M. (2020). The moderating effect of analytical decision-making culture on the relationship between business intelligence drivers and organisational agility: Empirical study in Jordanian banking sector.

Global Journal of Information Technology: Emerging Technologies. 10(2), 113-127. https://doi.org/10.18844/gjit.v10i2.4763

[19] R. F. Hurley and G. T. M. Hult, "Innovation, market orientation, and organizational learning: an integration and empirical examination," J. Marketing, vol. 62, no. 3, pp. 42-54, 1998.

[20] B. Ives and G. Piccoli, "Custom made apparel and individualized service at Lands' End," Commun. Assoc. Inform. Syst., vol. 11, no. 1, p. 3, 2003.

[21] G. Johnson, K. Scholes, and R. Whittington, Exploring Corporate Strategy: Text and Cases, 7th ed. Boston, MA, USA: Pearson Education Limited, 2008.

[22] H. Liu, W. Ke, K. K. Wei, and Z. Hua, "The impact of IT capabilities on firm performance: The mediating roles of absorptive capacity and supply chain agility," Decis. Support Syst., vol. 54, no. 3, pp. 1452-1462, 2013.

[23] A. Lönnqvist and V. Pirttimäki, "The measurement of business intelligence," Inf. Syst. Manage., vol. 23, no. 1, pp. 32-40, 2006.

[24] Y. Lu and K. Ramamurthy, "Understanding the link between information technology capability and organizational agility: An empirical examination," MIS Quart., pp. 931-954, 2011.

[25] B. Mróz, "Tworzenie wartości dla konsumentów na rynku dóbr luksusowych," in Zarzqdzanie wartościq klienta. Pomiar i strategie, B. Dobiegała-Korona and T. Doligalski, Eds. Warsaw, Poland: Poltext, 2010, pp. 283-284.

[26] M. Z. Elbashir, P. A. Collier, and M. J. Davern, "Measuring the effects of business intelligence systems: The relationship between business process and organizational performance," Int. J. Accounting Inf. Syst., vol. 9, no. 3, pp. 135-153, 2008.

[27] A. Maune, "Competitive intelligence and firm competitiveness: An overview," Corporate Ownership Control, vol. 11, no. 1, pp. 533-542, 2014.

[28] S. Negash, "Communications of the association science and information systems department," Kennesaw State Univ., Kennesaw, GA, USA, Tech. Rep., 2004, vol. 13, pp. 177-195. Iquery\{2\}\{Please provide the report no. for Ref. [31].\}

[29] E. Overby, A. Bharadwaj, and V. Sambamurthy, "Enterprise agility and the enabling role of information technology," Eur. J. Inf. Syst., vol. 15, no. 3, pp. 120-131, 2006.

[30] A. Popovič, R. Hackney, P. S. Coelho, and J. Jaklič, "Towards business intelligence systems success: Effects of maturity and culture on analytical decision making," Decis. Support Syst., vol. 54, no. 1, pp. 729-739, 2012.

[31] P. G. Kolaitis, Eds., Proceedings of the 21st ACM SIGMOD-SIGACT-SIGART Symposium on Principles of Database Systems. New York, NY, USA: ACM, 2002, pp. 233-246.

[32] P. B. Seddon, C. Calvert, and S. Yang, "A multi-project model of key factors affecting organizational benefits from enterprise systems," MIS Quart., vol. 34, no. 2, pp. 305-328, 2010.

[33] P. Trkman, K. McCormack, M. P. V. de Oliveira, and M. B. Ladeira, "The impact of business analytics on supply chain performance," Decis. Support Syst., vol. 49, no. 3, pp. 318-327, 2010.

[34] A. Rezvani, L. Dong, and P. Khosravi, "Promoting the continuing usage of strategic information systems: The role of supervisory leadership in the successful implementation of enterprise systems," Int. J. Inf. Manage., vol. 37, no. 5, pp. 417-430, 2017.

[35] N. Roberts and V. Grover, "Leveraging information technology infrastructure to facilitate a firm's customer agility and competitive activity: An empirical investigation," J. Manage. Inform. Syst., vol. 28, no. 4, pp. 231-270, 2012.

[36] R. Sharma and P. Yetton, "The contingent effects of management support and task interdependence on successful information systems implementation," MIS Quart., vol. 27, no. 4, pp. 533-555, 2003.

[37] S. M. de Alwis and S. E. Higgins, "Information as a tool for management decision-making: A case study of Singapore," in Information Research, 2001. Iquery\{2\}\{Please provide the publisher name and publisher location for Refs. [41] and [45].\}

[38] Y. Y. Yusuf, D. Al-Dabass, A. Gunasekaran, and J. A. Ren, "A mathematical modelling framework for agile manufacturing systems," in Proc. Conf. Proc. Uk Simulation Soc., Cambridge, U.K., Mar. 2001, pp. 216-222.

[39] C. H. Sampaio, W. J. Ladeira, and F. D. O. Santini, "Apps for mobile banking and customer satisfaction: A cross-cultural study," Int. J. Bank Marketing, vol. 35, no. 7, pp. 1133-1153, 2017. 
AL-Hanandeh, R. M. (2020). The moderating effect of analytical decision-making culture on the relationship between business intelligence drivers and organisational agility: Empirical study in Jordanian banking sector.

Global Journal of Information Technology: Emerging Technologies. 10(2), 113-127. https://doi.org/10.18844/gjit.v10i2.4763

[40] L. Sen, T. Felix, and E. Felix, "The understanding the effect of cloud computing on organizational agility: An empirical examination," Int. J. Inf. Manage., vol. 43, no. 2018, pp. 98-111, 2007.

[41] A. Shollo and R. D. Galliers, "Towards an understanding of the role of business intelligence systems in organisational knowing," Inf. Syst. J., vol. 26, no. 4, pp. 339-367, 2015.

[42] D. J. Teece, G. Pisano, and A. Shuen, "Dynamic capabilities and strategic management," Strategic Manage. J., vol. 18, no. 7, pp. 509-533, 1997.

[43] Y.-H. Tseng and C.-T. Lin, "Enhancing enterprise agility by deploying agile drivers, capabilities and providers," Inf. Sci., vol. 181, no. 17, pp. 3693-3708, 2011.

[44] C.-T. Lin, H. Chiu, and Y.-H. Tseng, "Agility evaluation using fuzzy logic," Int. J. Prod. Econ., vol. 101, no. 2, pp. 353-368, 2006.

[45] W. W. Chin, "Issues and opinion on structure equation modeling," MIS Quart., vol. 22, no. 1, pp. vii-xvi, 1998.

[46] C. Vercellis, Business Intelligence: Data Mining and Optimization for Decision Making, A. Ahmadi and A. Mohebbi, Eds., 2nd ed. Tehran, Iran: Amirkabir Univ. Press, 2013.

[47] Z. Zhang and H. Sharifi, "Towards theory building in agile manufacturing Strategy--A taxonomical approach," IEEE Trans. Eng. Manag., vol. 54, no. 2, pp. 351-370, May 2007.

[48] Z. Jourdan, R. K. Rainer, and T. E. Marshall, "Business intelligence: An analysis of the literature," Inf. Syst. Manage., vol. 25, no. 2, pp. 121-131, 2008.

\section{Appendix A. Measurement questionnaire items}

\begin{tabular}{|c|c|c|c|}
\hline Construct & Items & Descriptions & Sources \\
\hline \multirow{3}{*}{ BDI } & BDI1 & Mobile application provides data everywhere in databases & \multirow{3}{*}{$\begin{array}{l}\text { Seddon et al. } \\
\text { (2010) }\end{array}$} \\
\hline & $\mathrm{BDI} 2$ & $\begin{array}{l}\text { Mobile application provides data in the sources are mutually } \\
\text { consistent }\end{array}$ & \\
\hline & $\mathrm{BDI} 3$ & Mobile application provides Data are completely integrated & \\
\hline \multirow{6}{*}{ BAC } & BAC1 & Mobile application provides Paper reports & \multirow{6}{*}{$\begin{array}{l}\text { Trkman } \\
(2010)\end{array}$} \\
\hline & BAC2 & This mobile application provides Interactive reports & \\
\hline & BAC3 & Mobile application provides On-line analytical processing (OLAP) & \\
\hline & BAC4 & $\begin{array}{l}\text { Mobile application provides Analytical applications, including } \\
\text { Trend analysis }\end{array}$ & \\
\hline & BAC5 & Mobile application provides Data mining tasks & \\
\hline & BAC6 & Mobile application provides Dashboards, including metrics, KPIs & \\
\hline \multirow{3}{*}{ ECC } & ECC1 & $\begin{array}{l}\text { This mobile application provides New initiatives of competitors in } \\
\text { banking sector }\end{array}$ & \multirow{3}{*}{$\begin{array}{l}\text { Tseng and Lin } \\
\text { (2011) }\end{array}$} \\
\hline & ECC2 & $\begin{array}{l}\text { Mobile application provides Competitors technological advance in } \\
\text { banking sector }\end{array}$ & \\
\hline & ECC3 & $\begin{array}{l}\text { Mobile application provides Increasing pressure on cost in banking } \\
\text { sector }\end{array}$ & \\
\hline \multirow{3}{*}{ ECM } & ECM1 & $\begin{array}{l}\text { Mobile application provides Decreasing new products time to } \\
\text { market in banking sector }\end{array}$ & \multirow{3}{*}{$\begin{array}{l}\text { Tseng and Lin } \\
\text { (2011) }\end{array}$} \\
\hline & ECM2 & $\begin{array}{l}\text { Mobile application provides Product lifetime shrinkage in banking } \\
\text { sector }\end{array}$ & \\
\hline & ECM3 & $\begin{array}{l}\text { Mobile application provides Increasing rate of change in product } \\
\text { models in banking sector }\end{array}$ & \\
\hline \multirow{4}{*}{ INC } & INC1 & Mobile application provides risk taking is encouraged in our firm & \multirow{4}{*}{$\begin{array}{l}\text { Hurley and } \\
\text { Hult (1998) }\end{array}$} \\
\hline & INC2 & Mobile application provides Creativity is encouraged in our bank & \\
\hline & INC3 & $\begin{array}{l}\text { Mobile application provides management actively seeks innovative } \\
\text { ideas }\end{array}$ & \\
\hline & INC4 & Mobile application provides management is tolerant to mistakes & \\
\hline
\end{tabular}


AL-Hanandeh, R. M. (2020). The moderating effect of analytical decision-making culture on the relationship between business intelligence drivers and organisational agility: Empirical study in Jordanian banking sector.

Global Journal of Information Technology: Emerging Technologies. 10(2), 113-127. https://doi.org/10.18844/gjit.v10i2.4763

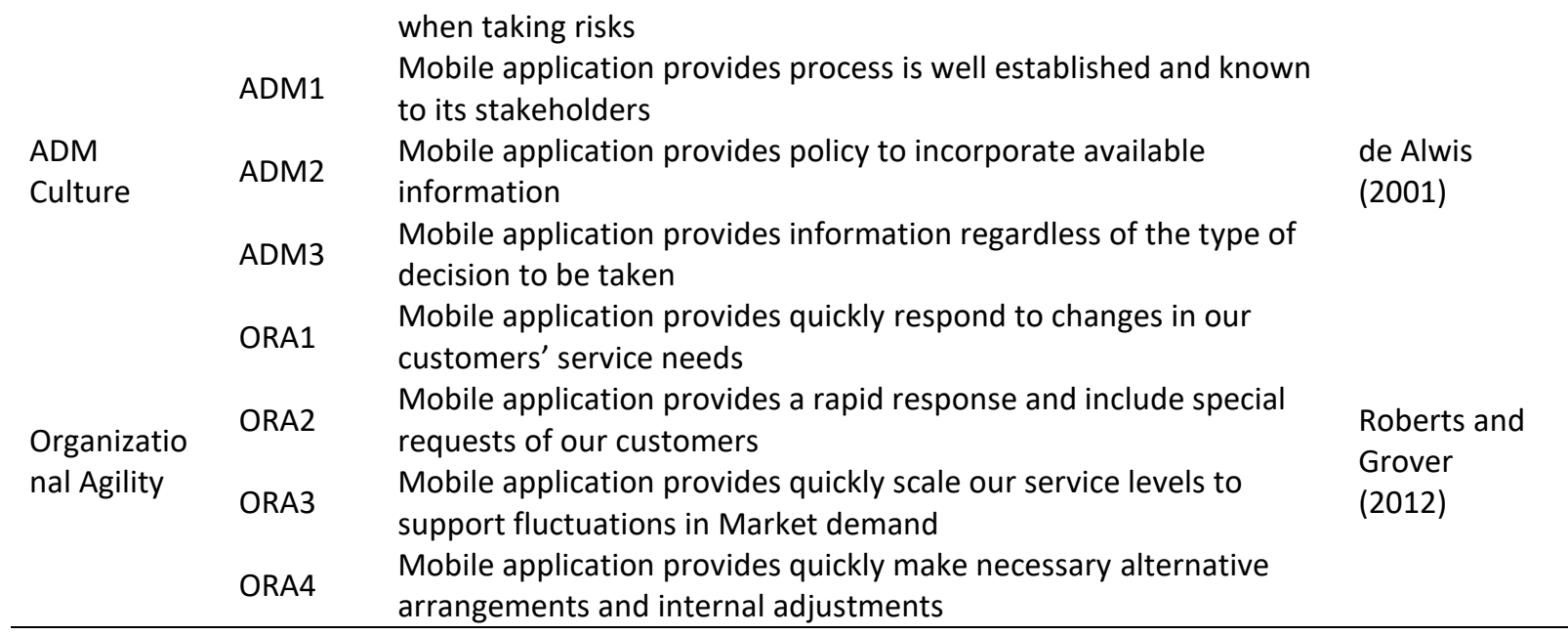

